\section{Vaccination and Smallpox}

Is the recent issue of The Fight against Disease (26, No. 1 ; 1938), the quarterly journal of the Research Defence Society, Dr. Monckton Copeman reviews the evidence of the value of vaccination as a preventive of smallpox. A striking instance is that of Soviet Russia, where vaccination was not made compulsory until 1918. In 1915 , there were 126,518 cases of smallpox ; in 1925, 18,514, and in 1929 only 6,406 cases. In the subsequent quinquennium, there was an increase in the incidence of the disease owing to laxity in carrying out vaccination, but more rigorous measures being adopted, the number of smallpox cases fell from 17,327 in 1934 to 3,156 in 1935 , and to 385 in 1936, while in the first quarter of 1937 not a single case was notified.

\section{The Treatment of Malaria}

ThE Malaria Commission of the Health Organisation of the League of Nations has published its fourth report. a valuable and important document, dealing with the treatment, and to a less extent with the prevention, of malaria (League of Nations. Bulletin of the Health Organisation, No 6. London: Allen and Unwin, 1937. 2s. 6d.). The Malaria Commission has been working for the last three years in making as exact a comparison as possible of the efficacy of quinine and the two synthetic drugs atebrin and plasmoquine for treatment of patients, for clinical prophylaxis, and for mass treatment and attempts at eradication of malaria. In treatment of an attack, quinine in daily doses of 1.0-1.3 gm., and atebrin in daily doses of 0.3 gm., are almost equally efficient in causing disappearance of the trophozoites of the three forms of fever-quartan, benign tertian and malignant tertian -atebrin having a somewhat more rapid action than quinine. Both these drugs also act upon the gametocytes of the quartan and benign tertian parasites, but have little or no action on those of the malignant tertian parasite. Plasmoquine is active upon the trophozoites of the quartan parasite, is less active upon the benign tertian, and is without action upon the malignant tertian. On the other hand, this drug is active upon the gametocytes of all three parasites, but particularly upon those of the malignant tertian parasite. The association of quinine with plasmoquine represents one of the most efficacious methods of treating malaria. It is interesting to note that quinine thus still maintains its place as one of the most efficient drugs in the treatment of malaria, and it has the advantage that with the usual doses it has little depressive or toxic effect, and is the safest drug to use without constant medical supervision.

\section{Earthquake in the Philippines}

ON Monday, August 29, during the night, an earthquake occurred in the Philippine Islands (The Times, Aug. 31). The epicentre was to the south-east of Manila between the islands of Masbate and Samar, since both these islands were affected, property being destroyed and several people being injured. No large earthquake has occurred in the Philippines since Batangas was destroyed just before 11 p.m. on the night of December 14, 1901, though small earth- quakes are common in that part of the world. The epicentre of the present shock is somewhat to the west of the most important seismic zone south of Manila. This latter is the ocean trough known as the Philippine Deep lying to the east of Mindanao. No fewer than 102 epicentres between 1920 and 1929 determined by Father W. G. Repetti, S.J., of the Manila Observatory, were found to lie chiefly in two areas concentrated on lat. $6^{\circ} 30^{\prime} \mathrm{N}$., long. $126^{\circ} 40^{\prime} \mathrm{E}$., and lat. $7^{\circ} 45^{\prime} \mathrm{N}$., long. $127^{\circ} 10^{\prime} \mathrm{E}$.

\section{The Los Angeles Earthquake}

A "STrong" earthquake is reported as having taken place on Tuesday night, August 30, in the neighbourhood of Los Angeles, but little damage is mentioned. A previous earthquake in Los Angeles occurred on January 28,1931 , at $12^{\mathrm{h}} 50^{\mathrm{m}}$ P.S.T., having its epicentre near the intersection of $48 \mathrm{th}$ Street and 2nd Avenue, Los Angeles $\left(34^{\circ} 00^{\prime}\right.$ N., $180^{\circ} 19^{\prime}$ W.), with intensity 4 on the Rossi-Forel scale, and affecting an area of about one and a half kilometres radius. The shock was studied by C. F. Richter of Pasadena, who stated that the epicentre was on the prolongation of the abrupt north face of the Baldwin Hills, previously considered an erosion feature, but now suspected to be a fault. The present earthquake bears many resemblances to its predecessor, and we await further details with interest.

\section{North of England Zoological Society}

THE North of England Zoological Society, which owns and controls the Chester Zoological Gardens, is making an appeal to raise funds to place the Society in a stronger financial position. The objects of the Society are to establish a public zoological garden for the purpose of keeping wild animals and birds in spacious enclosures so that they can be admired and studied in safety. The Society is bound by its memorandum of association to use all its income for the promotion of its objects; it is not allowed to have a share capital, hence the necessity for raising a fund for this purpose. Further information can be obtained from the Secretary, North of England Zoological Society, Zoological Gardens, Upton-uponChester.

\section{Effect of Floods in East Norfolk}

Mr. E. V. NEwnhaM, referring to his letter in Nature of August 6, states that the date of the severe gale mentioned by him should have been June 29, that is to say, it came nearly at spring. tide. Further, in line 3 of the penultimate paragraph of the letter, 'sledge-covered' shallows should be read 'sedge-covered' shallows. Mr. Newnham continues: "I have not yet studied in detail the official statistics relating to the general character of the weather in the autumn and winter following a spring drought like that of 1938, but Dr. C. E. P. Brooks of the Meteorological Office is of the opinion that the statistics will show that more than the average degree of storminess over England is usual. It is to be hoped that those gales that blow from the northwest will not come at spring tides". 